\title{
Comparison of several elements and their performances in static and dynamic FEA
}

\author{
Nitesh Bandewar ${ }^{+*}$ and Sanjay Deshpande ${ }^{\ddagger}$ \\ ${ }^{\dagger}$ Mechanical Department, P. V. G.'s C. O. E. T., SSP Pune, India \\ ¥Mechanical Department, K. C. O. E.,SSP Pune, India \\ Accepted 02 March 2016, Available online 15 March 2016, Special Issue-4 (March 2016)
}

\begin{abstract}
Cantilever structures are found in almost all engineering branches and in practise. A tall chimney, a dead end of a piping system, aircraft wing, heat exchanger fins or a tall multi-storeyed building in civil engineering and several components in mobile system and aerospace system can also be treated at a first hand as one end fixed and other free kind of configurations. We also find that recently in nanotechnology typically the new technologies such as photostrictive materials are usually tested on standard configurations so as to know the effect on the original structure. FEA plays a very important role in the overall mechanical design process. It has been applied successfully to almost all kinds of problems, which range from statics to dynamics. Although we find lot of literature on static analysis with respect to verification and validation of result, this is not always the case with respect to dynamic problems in frequency and time domain due to complexity of physics and numeric. The man motive in this work is to consider a cantilever structure model such that the frequencies vary from few $\mathrm{Hz}$ to $\mathrm{MHz}$ range and analyse the natural frequency calculation accuracy on a given mesh. We show that the FEA results deviates much from exact solution for natural frequency calculations. This means if a user is to consider a selected frequency of interest and if that is not captured by FEA then suitable element and mesh has to be considered rather than a blind use of FEA software. It is expected that the users will benefit from the understanding we had from this work.
\end{abstract}

Keywords: FEA, Jacobian, Beam model,natural frequency,BEM,CAE,TRAI3,TETRA,PENTA, photostrictive, etc.

\section{Introduction}

Computer Aided Engineering (CAE) is the third dimension of engineering supplementing the other two dimensions of pure theory and experiment. Finite Element Method (FEM) has been the main numerical technique used for analysis as compared to the other methods such as Finite Difference method (FDM) and Boundary Element Method (BEM). The finite element analysis is the modeling of products and systems in a virtual environment, for the purpose of finding and solving potential (or existing) structural or performance issues. FEA is the practical application of the finite element method (FEM), which is used by engineers and scientist to mathematically model and numerically solve very complex structural, fluid, and meta-physics problems. FEA software can be utilized in a wide range of industries. It has also become an

*Corresponding author: Nitesh Bandewar integral part of design process. Although much has been talked on static problems and several softwares/codes are available, in literature we find less verification and validation on standard problems with respect to dynamics.

The present work analyses one standard configuration of a cantilever beam and we put forward the behavior of several finite elements from one dimension to 3-dimensions in this paper. We discover that there are still lot of unanswered questions when it comes to the interpretation of results in static and dynamic simulations and these need to be taken care of by the user of the software. Physical understanding is much more important and its correlation to the numerical with respect to element plays a very important role. Further situation is more complex for practical problems as several mesh quality parameters such as distortion or Jacobian, aspect-ratio, skew or taper, min and max angles of the element come into picture. 


\section{The Problem and Exact Solution}

The problem we have taken for analysis is a cantilever beam made of steel (Young's modulus $=2.1 \times 10^{5} \mathrm{MPa}$, $\rho=7800 \mathrm{~kg} / \mathrm{m}^{3}$ ). Cross-section of the beam in y-z Plane is $1 \times 3 \mathrm{~mm}$.

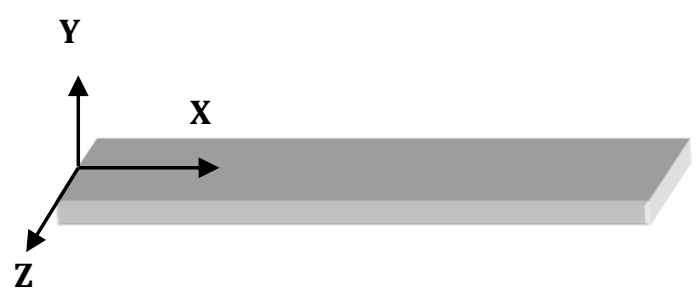

i. Displacement

$\delta_{1}=\frac{\mathrm{Pl}^{3}}{3 \mathrm{EI}_{\mathrm{zz}}}=6.34 \mathrm{~mm}$

Where, $P=1 \mathrm{~N}$,

$\mathrm{l}=100 \mathrm{~mm}$,

$\mathrm{E}=2.1 \times 10^{5} \mathrm{~N} / \mathrm{mm}^{2}$,

and the moment of inertia $\mathrm{I}_{\mathrm{zz}}=0.25 \mathrm{~mm}^{4}$

This is the standard Strength of Materials solution which can be found in any book.

\section{ii. Stress}

$\sigma=\frac{\mathrm{My}}{\mathrm{I}_{\mathrm{zz}}}=200 \mathrm{MPa}$

Where, $\quad M=100 \mathrm{Nmm}$,

$\mathrm{y}=0.5 \mathrm{~mm}$

and the moment of inertia $\mathrm{I}_{\mathrm{zz}}=0.25 \mathrm{~mm}^{4}$.

iii. Natural Frequencies

The cantilever structure is a continuous type of system and has infinite natural frequencies but we have considered first ten natural frequencies in this paper. A standard formula in the literature [3] is

$f n=\frac{c n}{2 \pi} \sqrt{\frac{E I_{z z}}{\rho A L^{4}}}$

where the first five coefficients are

$c 1=1.875, c 2=4.694, c 3=7.855, c 4=10.995$ and

$\mathrm{c} 5=14.136$

Consideration of each Moment of inertia i.e. $\mathrm{I}_{\mathrm{ZZ}}$ and $\mathrm{I}_{\mathrm{YY}}$ gives us two frequencies and hence we calculate the first ten natural frequencies of the structure as
Where, $\mathrm{E}=2.1 \times 10^{5} \mathrm{~N} / \mathrm{mm}^{2}$

$\mathrm{L}=100 \mathrm{~mm}$

$\rho=7.8 \times 10^{-9}$ tonne $/ \mathrm{mm}^{3}$

$\mathrm{A}=3 \mathrm{~mm}^{2}$

$I_{z z}=0.25 \mathrm{~mm}^{4}$

2. $f_{2}=\frac{1.875^{2}}{2 \pi} \sqrt{\frac{E I_{y y}}{\rho A L^{4}}}=253.88 \mathrm{~Hz}$

where $\mathrm{I} y y=2.25 \mathrm{~mm}^{4}$ and other parameters are the same.

3. $f_{3}=\frac{4.694^{2}}{2 \pi} \sqrt{\frac{E I_{z z}}{\rho A L^{4}}}=524.25 \mathrm{~Hz}$

4. $f_{4}=\frac{4.694^{2}}{2 \pi} \sqrt{\frac{E I_{y y}}{\rho A L^{4}}}=1572 \mathrm{~Hz}$

5. $f_{5}=\frac{7.855^{2}}{2 \pi} \sqrt{\frac{E I_{Z z}}{\rho A L^{4}}}=1470.9 \mathrm{~Hz}$

6. $f_{6}=\frac{7.855^{2}}{2 \pi} \sqrt{\frac{E I_{y y}}{\rho A L^{4}}}=4412.7 \mathrm{~Hz}$

7. $f_{7}=\frac{10.995^{2}}{2 \pi} \sqrt{\frac{E I_{Z z}}{\rho A L^{4}}}=2881.923 \mathrm{~Hz}$

8. $f_{8}=\frac{10.995^{2}}{2 \pi} \sqrt{\frac{E I_{y y}}{\rho A L^{4}}}=8645.77 \mathrm{~Hz}$

9. $f_{9}=\frac{14.136^{2}}{2 \pi} \sqrt{\frac{E I_{Z z}}{\rho A L^{4}}}=4763.706 \mathrm{~Hz}$

10. $f_{10}=\frac{14.136^{2}}{2 \pi} \sqrt{\frac{E I_{y y}}{\rho A L^{4}}}=14291.117 \mathrm{~Hz}$

\section{Finite Element Modeling}

We have used 8 elements in a length of $100 \mathrm{~mm}$ for all the models from one dimension to three dimension. i.e. 8 beam elements were considered in one dimension, $8 \mathrm{x} 1$ mesh was used for shell element two dimensional representation and $8 \times 1 \times 1$ mesh for three dimensional representation. A typical representation of these meshes is shown in the figures given below.

Fig. 1. Bem Model

1. $f_{1}=\frac{1.875^{2}}{2 \pi} \sqrt{\frac{E I_{Z z}}{\rho A L^{4}}}=84.62 \mathrm{~Hz}$

Fig. 2. TRIA Model 


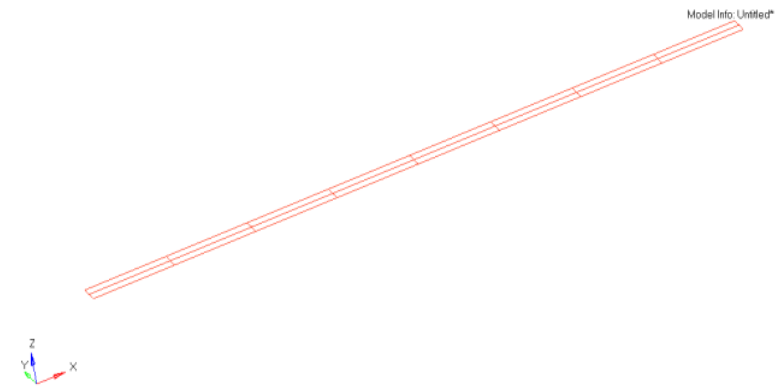

Fig. 3. QUAD Model

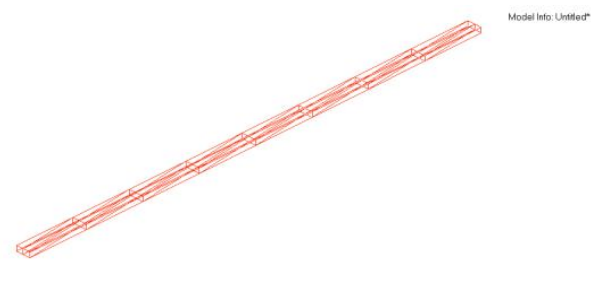

Fig. 4. TETRA Model

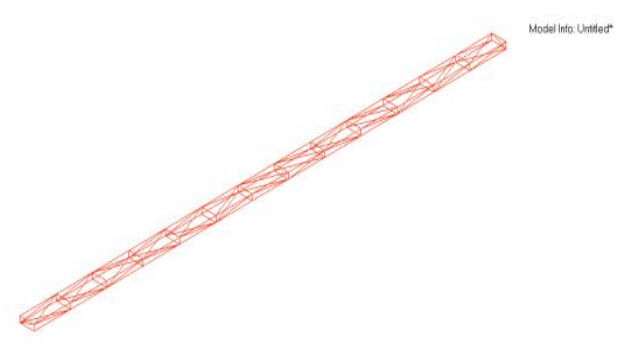

Fig. 5. PENTA Model

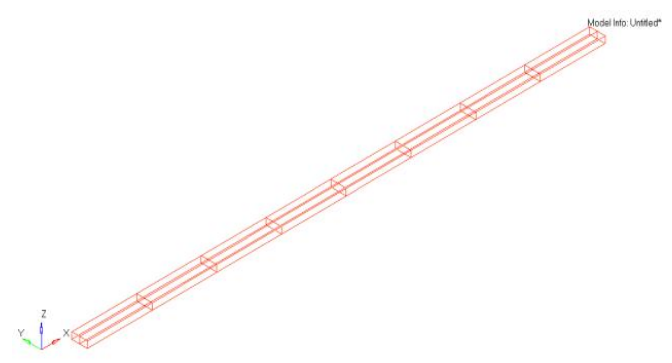

Fig. 6. HEXA8 Model

\section{FEA Results}

The results for each element have been tabulated here. We also give a comparison of exact solution vs. the FEA solution for each element so that it is understood by the user.

Table 1Dynamic Results

\begin{tabular}{|c|c|c|c|c|c|c|c|c|c|c|}
\hline Mode No. & EXACT & BEAM & TRIA3 & TRIA6 & QUAD4 & QUAD8 & $\begin{array}{l}\text { TETRA4 } \\
\end{array}$ & TETRA10 & PENTA & HEXA8 \\
\hline 1 & 84.62 & 83.037 & 84.134 & 83.934 & 83.761 & 83.896 & 549.507 & 83.288 & 84.371 & 83.989 \\
\hline 2 & 253.88 & 249.013 & 518.827 & 252.113 & 251.651 & 251.200 & 1066.631 & 249.172 & 528.857 & 254.029 \\
\hline 3 & 524.25 & 508.669 & 1153.093 & 525.778 & 516.524 & 525.429 & 3642.972 & 525.913 & 1156.875 & $\begin{array}{l}526.509 \\
\end{array}$ \\
\hline 4 & 1572 & 1395.440 & 1437.234 & 1472.077 & 1428.398 & 1470.100 & 5599.945 & 1487.248 & 1507.601 & $\begin{array}{l}1499.147 \\
\end{array}$ \\
\hline 5 & 1470.9 & 1521.856 & 2790.206 & 1596.777 & 1571.495 & 1568.135 & $\begin{array}{l}9824.528 \\
\end{array}$ & 1568.635 & 3080.873 & $\begin{array}{l}1587.346 \\
\end{array}$ \\
\hline 6 & 4412.7 & 2675.007 & 3294.584 & 2888.589 & 2767.835 & 2878.686 & 13060.53 & 2971.001 & 3955.420 & 3060.135 \\
\hline 7 & 2881.92 & 4158.559 & 4586.063 & 4546.363 & 3562.411 & 4298.599 & 15446.89 & $\begin{array}{l}4230.098 \\
\end{array}$ & 5525.370 & $\begin{array}{l}3769.604 \\
\end{array}$ \\
\hline 8 & 8645.77 & 4294.042 & 6744.069 & 4594.034 & 4442.262 & 4365.554 & 19880.87 & 4418.615 & 6844.260 & 4499.603 \\
\hline 9 & 4763.7 & 4513.207 & 6826.054 & 4796.913 & 4518.742 & 4757.308 & 27520.23 & 5039.961 & 9533.609 & 5479.741 \\
\hline 10 & 14291.12 & 6060.616 & 9020.878 & $\begin{array}{l}7237.455 \\
\end{array}$ & 6596.528 & 7111.984 & 30817.68 & $\begin{array}{l}7717.752 \\
\end{array}$ & 11907.08 & 9111.109 \\
\hline
\end{tabular}

Table 2 Static Results

\begin{tabular}{|c|c|c|c|c|c|c|c|c|c|c|}
\hline & EXACT & BEAM & TRIA3 & TRIA6 & QUAD4 & QUAD8 & TETRA4 & TETRA10 & PENTA & HEXA8 \\
\hline Displacement (mm) & 6.34 & 6.349 & 6.24 & 6.336 & 6.287 & 6.339 & 0.138 & 6.407 & 6.219 & 6.264 \\
\hline $\begin{array}{l}\text { Stress at Fixed End } \\
\text { (MPa) }\end{array}$ & 200 & 200 & 177.707 & 205.637 & 193.787 & 201.986 & 150.257 & 147.781 & 113.381 & 193.832 \\
\hline
\end{tabular}

\section{Conclusions}

It is observed from the table that most of the elements perform very well in static except TRIA3 and TETRA4 and PENTA which is a well known fact that these are stiff elements and predict the displacements to a low value. However the answer to the question on interpretation of how much stiff, comes from the dynamic results for natural frequency as it is here that mass of the structure remains the same and frequency value gives an indication of the stiffness of the element.We also observe that the higher order elements TRIA6 and QUAD8 over predict the stress , a fact not so well known in the CAE community.
The beam element predicts the first five modes correctly but we see a lot of deviation from sixth to tenth mode. The same is true for almost all the elements but at higher modes we can see a good level of accuracy from the HEXA element. One should not come to a conclusion that the performance of PENTA is better at higher frequencies which is pure coincidence ,in fact the deviations for low frequency for such elements are much higher.

The question on which is the best element probably remains still unanswered with studies of mesh refinement and is the scope of future work. We are of the opinion that here the scope of experimental analysis is more critical and should be more 
encouraged. How do these values compare with experimental ones can also be a good research topic. Probably the finite element user keeps always in his mind the co-relation of a suitable mesh and exptal value pertaining a particular mode shape and should validate the finite element model accordingly for further studies on Noise, Vibration and Harshness and transient dynamics events.

\section{References}

Jadhav M., Darade P., Deshpande S. S., 2015, "On the Accuracy of Finite Element Method for Static and Dynamic Problem", International Journal of Engineering Trends and Technology(to appear), presented at International conference on Global trends in Engg., Technology and Management, Jalgaon , India ,4-6 Jan 2016.

Ramamrutham S., Strength of Materials, Dhanpat Rai Publication, 2014 .

Rao S.S, Mechanical Vibrations, $5^{\text {th }}$ edition,Pearson Education India. 